\title{
LAS NORMAS Y SU PUESTA EN VIGOR: RESPUESTA A JOSEP CORBÍ
}

\author{
MANUEL GARCÍA-CARPINTERO \\ LOGOS-Departament de Filosofia \\ Universitat de Barcelona \\ m.garciacarpintero@ub.edu
}

RESUMEN: En su discusión "Obras de ficción, formas de conciencia y literatura", Josep Corbí formula una serie de críticas certeras a mis ideas sobre la distinción que he hecho entre ficción y no ficción en Relatar lo ocurrido como invención (2016). En esta nota de respuesta expongo primero de forma sucinta el núcleo de esas ideas y después proporciono las que considero las razones más decisivas para adoptarlas, a pesar de las dificultades que señala Corbí.

PALABRAS CLAVE: ficción, no ficción, actos de habla, aseveración, literatura

SUMMARY: In his paper "Obras de ficción, formas de conciencia y literatura", Josep Corbí raises a few sharp objections to my distinction between fiction and non-fiction, as I formulate it in my recently published Relatar lo ocurrido como invención (2016). In this response, I present first in a compact form such ideas, and then I try to answer to Corbí's criticisms.

KEY WORDS: fiction, non-fiction, speech acts, assertion, literature

En su informada y penetrante discusión de mi obra Relatar lo ocurrido como invención: una introducción a la filosofía de la ficción contemporánea (2016) intitulado "Obras de ficción, formas de conciencia y literatura", además de propocionar un lúcido sumario del contenido del libro, Josep Corbí formula una serie de críticas certeras. Es posible que cierta falta de claridad en la presentación de mis ideas en el libro y en los textos relacionados en que se apoya Corbí contribuya a exponerlas a objeciones como las suyas, aunque no se me escapa que son en sí mismas capaces de suscitar el tipo de cuestiones que Corbí expresa. En esta nota de respuesta expondré primero sucintamente el núcleo de tales ideas, lo que espero que contribuya a dibujar más claramente sus contornos esenciales, y señalaré las que considero las razones más decisivas para adoptarlas, a pesar de las dificultades que señala Corbí. Quiero consignar de antemano mi agradecimiento a Josep Corbí: nada proporciona mayor satisfacción y reconocimiento a un autor que las lecturas perceptivas y críticas de su trabajo, como la suya. 


\section{Normas constitutivas y normas vigentes}

En el núcleo de las tesis sobre la distinción entre ficción y no ficción que defiendo en el libro está la idea, que tomo de Searle y Currie, de que la distinción debe hacerse en los términos propios de la teoría de los actos de habla, bajo el supuesto de que una ficción es el producto de un acto comunicativo. Mi posición sobre los actos del habla es (como en otras cuestiones de filosofía, pues a mi juicio el estilo filosófico es un producto más del carácter propio) fundamentalmente conservadora y ecuménica, ${ }^{1}$ con el riesgo de inconsistencia que ello conlleva. Por un lado, defiendo una línea wittgensteinianoaustiniana, según la cual los actos de habla son normativos en su naturaleza y la fuente de su normatividad se halla en las prácticas sociales, que en algunos casos son convenciones. Por otro, habilito un lugar significativo — si bien no definicional - para las intenciones comunicativas que en la concepción griceana los constituyen.

Las diferencias entre austinianos y griceanos son sutiles - y el no filósofo puede permitirse ignorarlas para cualquier propósito práctico relevante- pero no por eso menos reales. Ni unos ni otros desconocen que, pongamos por caso, sometemos a evaluación deóntica y axiológica las promesas, y criticamos en particular aquellas cuyos autores las incumplen. Al filósofo le importa la cuestión de si esto refleja lo que las promesas son en sí mismas, es decir, lo que las constituye o está en su naturaleza o esencia. El griceano lo niega y sostiene que sólo son propiedades descriptivas, y no evaluativas, las que constituyen qué es prometer: en particular, se trata de intenciones comunicativas de cierto tipo por parte de sus autores, quizás la de promover la expectativa de su cumplimiento en su audiencia a partir del reconocimiento de esa misma intención. Las normas y los valores que les aplicamos a las promesas se derivan de su carácter no normativo esencial, pues son otras sus fuentes normativas: presumiblemente, la moral, por medio de un principio que condena (salvo que medien circunstancias revocadoras) que generemos expectativas infundadas en nuestros semejantes (Scanlon 2003). El austiniano, por el contrario, sostiene que las promesas están constituidas por normas o valores, como los juegos.

En un influyente artículo, Rawls (1955) considera el caso particular de las promesas y distingue las nociones de norma constitutiva y norma regulativa. Searle (1969) utilizó esa distinción en su también

\footnotetext{
${ }^{1}$ En un sentido profundo de ambas palabras, que es compatible con el rechazo de muchas posiciones caracterizadas así sobre política o moral, y que incluso, a mi parecer, requiere dicho rechazo.
} 
influyente caracterización de los actos de habla. A mi juicio, la literatura sobre estos temas manifiesta sobradamente que la noción de norma constitutiva ha suscitado considerable confusión; y una de las razones que ha llevado al presente renacimiento de las concepciones austinianas de los actos de habla está en la clarificación que proporcionó Williamson (1996[2000]) en su articulación de una norma constitutiva para la aseveración.

En la propuesta de Williamson, los actos de habla, como los juegos, estarían definidos mediante normas, que en este caso tendrían un carácter particularmente simple. En especial, la aseveración sería el único acto tipo tal que, por su naturaleza, quien lo lleva a cabo hace algo incorrecto o ilegítimo si no sabe lo que asevera. Esta norma del conocimiento para aseverar es constitutiva en cuanto que define unívocamente qué es aseverar: es algo de carácter normativo, en cuanto que esencialmente se puede hacer bien o mal; ese único acto es tal que, por su carácter propio, se hace mal cuando el agente no sabe lo que asevera. Para el griceano, ésta y otras normas son sin duda normas de la aseveración: estándares con arreglo a los cuales evaluamos las aseveraciones como buenas o malas, legítimas o ilegítimas. Pero tales estándares son meramente regulativos, en cuanto que no definen el tipo de entidad que son. Para definirlos debemos mencionar únicamente rasgos descriptivos, psicológicos en particular: cierto tipo de intención comunicativa por parte del agente, quizás la de llevar a la audiencia a pensar que el agente cree lo que asevera a través del reconocimiento de esa misma intención.

El mérito de Williamson estriba, a mi parecer, en haber formulado de una manera perspicua la distinción de Rawls entre normas regulativas y constitutivas. Entiendo que lo que he resumido en el párrafo anterior es suficientemente claro: la idea de tipos de naturaleza normativa, definidos unívocamente por las condiciones en que sus ejemplares son correctos o incorrectos. Williamson ofrece además una serie de argumentos para entender la aseveración de ese modo. Otros hemos aceptado la idea general de que la aseveración está definida mediante normas constitutivas; sin embargo, cada uno propone normas alternativas. Algunos proponen normas más débiles, que consideran correctos todos los actos que cumplen con la norma del conocimiento, pero también otros que la incumplen, como la regla de que sólo la falsedad de lo dicho o la ausencia de legitimidad epistémica hacen incorrectas las aseveraciones. Junto con otros, yo propongo una norma más exigente, según la cual es la imposibilidad de que la audiencia adquiera el conocimiento de lo aseverado lo que hace incorrecta una aseveración. Este debate no es relevante 
aquí. Sí lo es, sin embargo, el hecho de que ni siquiera Williamson parezca comprender cabalmente la noción de tipos de norma constitutiva.

Esto se pone de relieve en la discusión de Williamson sobre la relación entre aseveración y convención. Es natural suponer que la fuente de la vigencia de muchas normas está en las convenciones sociales. Es de notar que, en su esbozo de marco para la caracterización general de los actos de habla, Austin suponía que esto es así en el caso de todos los actos de habla, algo que Strawson (1964) cuestionó convincentemente, con lo cual ofreció una justificación indirecta para la concepción griceana. Los actos de habla del tipo que Searle llama declaraciones, como casar o sentenciar a alguien, sí se ejecutan con arreglo a convenciones. Pero no parece haber convenciones que rijan la ejecución de muchos actos de habla indirectos, como aquellos que se efectúan, a grandes rasgos, siguiendo el modelo de lo que Grice (1975[1991]) caracterizaba como implicaturas conversacionales.

Quizás en vista del fracaso previo de Austin, a Williamson le importa mucho distinguir su propuesta sobre la aseveración como un tipo constitutivamente normativo de la idea de los actos convencionales. Argumenta, así, no sólo que los tipos constitutivamente normativos no tienen por qué ser convencionales, sino que no pueden serlo (1996[2000], p. 239). Su argumento es incuestionable dado lo que supone que son los tipos constituidos normativamente; sin embargo, si lo entendemos como una refutación a las tesis convencionalistas sobre los actos de habla como las que han defendido filósofos como Michael Dummett o las que quizás tenían en mente Austin o Wittgenstein, su argumento es un non sequitur, por cuanto esas tesis convencionalistas genuinamente interesantes no conciernen per se a los tipos williamsonianos. Para apreciarlo así, debemos reparar en que las normas que definen tales tipos no precisan estar vigentes.

Algunas personas encuentran un pasatiempo agradable en inventar variantes de fútbol que quizás podrían dar lugar a un juego más satisfactorio en determinados aspectos. Muchas de esas variantes, todas quizás, nunca darán lugar a un juego que realmente practique alguien. De hecho, como el propio Williamson observa (1996[2000], p. 239), el fútbol que sí se practica realmente, cuyas normas constitutivas obligan realmente a Cristiano Ronaldo, Messi y otros, no ha estado definido siempre mediante las mismas normas constitutivas, sino que éstas han ido cambiando a lo largo del tiempo. Algunas normas que definieron el juego en una época anterior ya no lo hacen 
ahora, no caracterizan juego alguno que nadie practique en estos momentos ni, por consiguiente, imponen realmente obligación alguna a nadie. Por tanto, no resulta inmediato identificar el fútbol que se juega realmente mediante un código de normas constitutivas.

Inspirado en un enfoque similar de la noción de lenguaje que ofrece Lewis (1975[1983]), Williamson propone que para entender esto hay que distinguir los tipos abstractos constituidos normativamente de su puesta en vigor en una práctica real. El fútbol que se practica realmente ha estado caracterizado propiamente en distintos momentos de su historia por distintos tipos abstractos; y algunos tipos abstractos con aspiraciones a definir el fútbol que se practica realmente no llegarán nunca a estar en vigor. Hecha esta distinción entre los tipos definidos normativamente en general y los tipos que están en vigor, Williamson (1996[2000], p. 239) establece que sus tesis se refieren a los primeros, esto es, a los tipos normativos entendidos meramente como tipos abstractos, independientemente de que estén o no vigentes, de que se hayan puesto en práctica o no.

Una vez que apreciamos esto, queda claro, como dije antes, que la tesis y el argumento anticonvencionalistas de Williamson son enteramente correctos respecto de tales entidades. El argumento apela a una disparidad modal: las normas constitutivas obligan necesariamente "en todos los mundos posibles"; las convenciones, sin embargo, son arbitrarias y por tanto sólo obligan contingentemente, en aquellas circunstancias en que han sido adoptadas. A todas luces, los tipos constituidos normativamente de Williamson, como cualquier entidad abstracta, no existen en virtud de convención alguna ni su fuerza normativa constitutiva depende de ninguna convención, mas debería resultar igual de claro que esta consideración modal es enteramente irrelevante para dirimir la corrección o incorrección de cualquier tesis convencionalista mínimamente plausible.

La razón es que, una vez formulada la distinción en los términos pertinentes que propone Williamson, resulta inmediato que las tesis convencionalistas deban referirse únicamente a aquello que explica que las normas constitutivas de tipo normativo vigentes realmente estén en vigor. Lo que el convencionalista sostiene no es que el tipo normativo en cuestión, en cuanto tal, sea resultado de una convención; esto es simplemente absurdo por lo dicho: ninguna entidad abstracta puede ser resultado de una convención. ${ }^{2}$ Lo que el

${ }^{2}$ Los filósofos con simpatías convencionalistas suelen sostener también puntos de vista nominalistas. Así pues, puede parecer que tales filósofos no se sentirán muy cómodos abordando estas cuestiones en los términos de Williamson, los cuales 
convencionalista sostiene es que son convenciones lo que explica que determinados tipos normativos vigentes realmente estén en vigor, obligando realmente a individuos reales. Así pues, no habría disparidad modal alguna. Si la vigencia de una práctica normativa depende de convenciones, tal práctica no estará vigente en todos los mundos posibles, ni tales normas obligarán necesariamente en el sentido en que lo hacen respecto de los individuos reales las normas que están realmente en vigor.

También es indudable que, en muchos casos, algunas tesis convencionalistas de este tipo deben ser verdaderas, por más que no sea nada simple articular con claridad lo que esto implica ni justificarlo. Por ejemplo, si, como Williamson piensa, la aseveración es normativa constitutivamente, también deben serlo los actos de habla en la categoría searliana de declaraciones a los que me referí antes; y parece natural pensar que, si determinados actos (constituidos normativamente) de esta categoría están vigentes, ello debe ser resultado de convenciones. Lo mismo es válido para los juegos, pues el que determinada forma abstracta de fútbol y no otra sea la que obliga ahora a Ronaldo y Messi es sin duda resultado de convenciones, en este caso, convenciones resultantes de acuerdos explícitos.

Lewis (1975[1983]) ofrece un complejo análisis griceano de las convenciones, que ha resultado, con toda razón, muy influyente, pero que ha sido cuestionado, con toda justicia, en la línea en que se suele hacer con tales análisis, en parte por lo implausible de su complejidad desde el punto de vista psicológico. En una propuesta más simple (Davis 2003, cap. 9) pero aun así influida por el trabajo de Lewis, las convenciones son prácticas que se llevan a cabo con regularidad en una comunidad y que permiten resolver un problema de coordinación de sus miembros - lo que explica su preservación-, pero que son arbitrarias en cuanto que existe una regularidad posible alternativa que habría satisfecho la necesidad suficientemente bien. No parece desencaminado aventurar una explicación así para la vigencia de las normas del fútbol o la de las declaraciones. En su detalle, tal explicación de la vigencia de las normas en cuestión apelaría a intenciones comunicativas griceanas; es aquí donde tales intenciones también desempeñan un papel en mi propuesta de una manera no

parecen simplemente dar por supuesta la existencia de las entidades abstractas. Este aparente platonismo, sin embargo, no es más que una conveniencia expositiva. En principio, podemos aplicar a esta forma de hablar reificadora de entidades como son los tipos normativos, en último extremo, el punto de vista ficcionalista que, como Corbí expone adecuadamente, defiendo en el libro, a propósito del lenguaje metafictivo en que reificamos con similar descaro los personajes de ficción. 
constitutiva o definicional. En la sección siguiente ilustraré esto con algún pormenor adicional.

Como recoge Corbí, tanto en el libro como con más detalle en un trabajo en que desarrollo las ideas resumidas aquí (García-Carpintero, s.a.) defiendo que los actos de habla más fundamentales (aseverar, prometer, requerir) no son convencionales después de todo. Concuerdo por tanto con la conclusión de Williamson, aunque no con sus razones. En su trabajo sobre convenciones, Lewis distingue entre estas y otras prácticas sociales a las que denomina contratos sociales. Tales prácticas también tienen la función de resolver problemas de coordinación, pero, a diferencia de las convenciones, no son arbitrarias: no existe una alternativa que tenga casi la misma adecuación para satisfacer sus objetivos. Asimismo, en el caso de las convenciones en condiciones normales, cualquier miembro de la comunidad que las pone en práctica prefiere desempeñar su papel en esa comunidad, siempre y cuando los otros también lo hagan, a no hacerlo. En el caso de los contratos sociales, sin embargo, los participantes preferirían que sólo los demás, pero no ellos mismos, se atuvieran a la práctica: los contratos sociales generan el tipo de problemas prácticos que en la teoría de los juegos se denomina dilema del prisionero.

A mi juicio, no hay, pongamos por caso, una alternativa a la práctica de aseverar, entendida normativamente, que hubiera servido para alcanzar el mismo objetivo —algo así como poner en común el máximo de información relevante socialmente-. Y algunos (Donald Trump es un ejemplo trágicamente obvio de ello) preferirían que sólo los demás se atuvieran a ella, sometiéndose a la reprobación cuando se usa para transmitir desinformación o información sin legitimidad epistémica. La práctica no se sostiene nada más sobre la prudencia y el cálculo racional, sino también sobre motivaciones del tipo de las que constituyen la moralidad (se identifiquen o no en último extremo con cierto tipo de consideraciones racionales). Lo mismo se aplica, a mi juicio, a los otros actos que he mencionado, las promesas y los requerimientos, y por ende también a hacer como que o a ficcionalizar, los cuales, según argumento en el libro, son un caso particular de estos últimos. Concedemos así, en parte, las ideas que atribuí antes a Scanlon, a propósito de las promesas, sin validar por ello una concepción griceana, no normativa, de su naturaleza.

Las propuestas presentadas sumariamente aquí requieren mucha más elaboración y justificación argumentativa, para lo que remito a los trabajos mencionados. Confío, sin embargo, en que baste esta presentación para hacer mínimamente claras y dignas de consideración las reflexiones que siguen en respuesta a las objeciones de Corbí. 


\section{Ficción, no ficción y la invocación de la imaginación}

Corbí presenta dos críticas centrales, respectivamente en las secciones 4 y 5 de su trabajo, que, si las interpreto bien, son variantes sugestivas de las objeciones de Stacie Friend (2008, 2011 y 2014) a los análisis de la distinción entre ficción y no ficción en términos de los actos de habla que invitan a la imaginación. La formulación que hago de un análisis de ese tipo (García-Carpintero 2013 y 2016a) aspira justamente a defender dichos análisis de las críticas de Friend, supuesto su carácter normativo; mas, como dije al comienzo, no se me escapa que la propuesta muy bien puede seguir suscitando reservas del mismo tenor. Creo que se podrán apreciar mejor mis respuestas a las críticas a partir de las consideraciones de la sección anterior, si expongo antes por qué la propuesta alternativa de Friend - con la cual Corbí parece simpatizar, véase la cita que ofrezco más adelanteme parece insatisfactoria y en su lugar es preferible alguna como la que he intentando formular.

Según Friend, ficción y no ficción son géneros, como el verismo en la ópera y el naturalismo en la literatura, o en la filosofía el carácter escolástico o analítico de un texto. Entiendo que los géneros se distinguen por poseer una naturaleza relacional: deben caracterizarse, por ejemplo, en términos de la relación de sus instancias con determinadas actitudes, propuestas o prácticas sociales con una particular datación espacio-temporal. Un texto producido en la Antigüedad clásica no puede ser, estrictamente hablando, filosofía analítica, ni verista una ópera de un contemporáneo de Lully. Por supuesto, podemos utilizar "verista" o "analítico" de manera metonímica o lata, como de hecho hacemos con muchas expresiones y quizás podemos hacer con cualquiera; con ello, clasificaríamos bajo esos términos páginas de Aristóteles y óperas barrocas, pero entiendo que no sería correcto hacerlo en el uso central, literal, de esos términos.

Hay versiones radicales de algunas propuestas del tipo de la de Friend que han llegado a ser muy conocidas, las cuales se deben a George Dickie y a otros; por ejemplo, que es arte aquello que el "mundo del arte" (críticos, galeristas, representantes, etc.) cuenta como tal. Hace poco, Sally Haslanger y otros han defendido propuestas similares para los géneros (en el sentido que se expresa en inglés con gender, frente a genre, que expresa el sentido con que Friend formula su tesis), masculino y femenino, o para las razas. Según estas propuestas, por ejemplo, algo entra dentro del género femenino si es sujeto de subordinación social en virtud de poseer determinadas características fenotípicas. 
A mi juicio, entendidas como propuestas descriptivas (es decir, sobre cómo entender un concepto en uso) y no como propuestas prescriptivas (sobre cómo deberíamos "reconstruir" el concepto para determinados fines teóricos o prácticos), estas ideas son erróneas a todas luces. Se han aducido diferentes consideraciones que así lo muestran (Neill y Ridley 2012), pero la más significativa a mi parecer es que esas propuestas relacionales no recogen cabalmente la dimensión axiológica o deontológica de hecho asociada conceptualmente con las nociones en cuestión. Así pues, que algo entre en la categoría de arte lo hace, en principio, merecedor de determinada apreciación, mas que algo sea considerado arte por el "mundo del arte" no lo hace eo ipso merecedor de tal apreciación - a menos que supongamos que ello es un buen indicio de que es arte, pero el defensor de las propuestas que estamos cuestionando no puede apoyarse en ese hecho sin circularidad - Q Que una persona sea clasificable dentro del género femenino o dentro de una raza contribuye a una explicación de que vea sometida (injustamente) a cierta subordinación, pero no explica en absoluto que de hecho esté sujeta a tal subordinación.

Hay propuestas alternativas que funcionan mucho mejor con arreglo al criterio anterior. No es preciso que hagan puramente intrínsecos los rasgos constitutivos de las categorías a que los conceptos en cuestión pretenden referir; pueden ser también relacionales, y cumplir sin embargo con el criterio apuntado. Por ejemplo, y en la misma línea de lo que propongo para los actos de habla, el arte puede ser una categoría normativa, cuyos ejemplares buenos o correctos poseen características generales que los hacen merecedores de determinado tipo de apreciación por parte de sujetos de cierto tipo. El género femenino o la raza caucásica pueden identificarse por rasgos biológicos no manifiestos — como cierta historia evolutivaque explican determinados rasgos fenotípicos manifiestos. En ambos casos, las categorías definidas así no son dependientes de prácticas sociales contingentes históricamente. Seres racionales en otras galaxias pueden tener arte, puede haber distinciones de género o de raza no asociadas a las prácticas discriminatorias propias de nuestra sociedad. Sean o no correctas, estas propuestas comparten el mérito de explicar las actitudes evaluativas asociadas, incluso cuando son actitudes reprobables, como en el caso de los géneros (masculino y femenino) y las razas.

En cuanto a la distinción entre ficción y no ficción, la propuesta de Friend es, a mi juicio, cuestionable por razones análogas. Si ello no es tan obvio, es porque su propuesta no es tan radical como las mencionadas. Friend apela a la distinción de Walton (1970) entre 
propiedades estándar, antiestándar y variables. Las primeras son aquellas que a primera vista llevarían a clasificar una obra en el género en cuestión (presentación descarnada de aspectos sociales y emociones poco gratos, en el caso del naturalismo o el verismo), las segundas aquellas que a primera vista hacen que una obra no pertenezca al género (temática pastoral o mitológica, en ambos casos). Según Friend, la invitación a la imaginación es una propiedad estándar de la ficción y la invitación a la creencia es una propiedad antiestándar (y estándar para la no ficción).

Como esa concesión incluye el tipo de teorías que a mí me parecen razonables, la propuesta de Friend no es tan claramente cuestionable como las mencionadas párrafos antes sobre la base del tipo de consideraciones apuntadas. Sin embargo, no está libre de objeciones, porque las propiedades estándar de un género no son más que rasgos que desempeñan contingentemente el papel descrito. Puede haber obras del género en cuestión que no las poseen (que poseen más bien propiedades antiestándar) y el mismo género, identificado por sus rasgos relacionales constitutivos, puede evolucionar de manera que lo que en un momento son propiedades estándar pasen a ser meramente variables, o incluso, a fin de cuentas, propiedades antiestándar. Ahora bien, mientras que esto es lo que sucede sin duda en el caso de lo que claramente son los géneros, así como en los casos que he venido mencionando a manera de ejemplo (hay autores analíticos o escolásticos cuyas obras no tienen en absoluto los rasgos estándares de tales géneros filosóficos), no parece ser así en cuanto a las categorías de ficción y no ficción. No veo cómo algo pueda clasificarse como ficción, sin que incluya una invitación a imaginar determinado contenido con arreglo al cual lo apreciamos, ni cómo algo sea clasificable como no ficción sin que incluya un compromiso con la verdad de su contenido.

Mas esta intuición no es la razón fundamental para dudar de la propuesta de Friend, según la cual son contingentes históricamente los hechos constitutivos de la distinción entre ficción y no ficción. La razón es, de nuevo, que la propuesta no permite explicar la evaluación que hacemos de los objetos en esas categorías. Friend no detalla cuáles son tales rasgos contingentes históricamente, pero aquellos que podemos colegir a partir de las categorías que sí son claramente géneros - como las que apuntamos líneas antes - no permiten explicar nuestras disposiciones evaluativas hacia las obras que clasificamos respectivamente como ficciones y no ficciones. Que un filme clasificado como documental tenga cierta conexión causal con sucesos que tuvieron lugar a principios del siglo XX — cuando al parecer se produjeron los primeros ejemplos del género- no explica por sí mismo que lo 
cuestionemos si presenta un contenido injustificadamente falso. O bien, no lo explica, de nuevo, a menos que el hecho de que el filme tenga tal origen causal conlleve que sea proclive al tipo de evaluación epistémica que hacemos de los documentales, pero Friend no puede apelar a esa posibilidad sin hacer que su propuesta sea circular. Por esa razón, y a diferencia de lo que sucede con lo que manifiestamente son los géneros, es razonable suponer que otras comunidades de seres racionales, desconectadas causalmente de las nuestras, bien puedan disponer de las categorías de la ficción y la no ficción.

Paso ahora a las objeciones de Friend para proseguir después con las de Corbí, las cuales - como dije - considero alternativas sugerentes e interesantes a las de Friend, quien insiste en la clasificación de las obras completas frente a la clasificación de sus partes. Correctamente, a mi juicio, considera a esta última al menos tan importante como la primera, y quizás incluso más básica para entender nuestra concepción de la distinción entre ficción y no ficción. Entonces señala que las obras que clasificamos como ficciones contienen de hecho partes que invitan a la creencia, y no nada más a la imaginación; mientras que las obras que clasificamos como de no ficción contienen partes que invitan a la imaginación. Para ilustrarlo mediante ejemplos de narrativas visuales, hay documentales clásicos de Herzog o Morris y otros más recientes como The Act of Killing (El acto de matar, 2012), de Oppenheimer, que contienen partes recreadas por actores profesionales o no profesionales; mientras que las películas de ficción del género biopic, como The Imitation Game (El código Enigma, 2014), nos invitan a creer que representan adecuadamente los contornos fundamentales de las vidas representadas y las cuestionamos si no lo hacen ( $c f r$. Caryl 2015). Las secciones 4 y 5 de la discusión de Corbí plantean objeciones basadas en consideraciones de ambos tipos.

Las observaciones de Friend -así como las análogas de Corbí, que discuto a continuación - son muy relevantes, porque se refieren a una cuestión importante a mi juicio, que abordo en mi libro y en otros trabajos mencionados (véase también García-Carpintero 2016b): la posibilidad de aprender o adquirir conocimiento a partir de la ficción. Friend sostiene - correctamente, a mi juicio- que tal posibilidad existe, en parte en virtud del hecho de que las ficciones contienen actos de habla del tipo que Austin clasificaba como constatativos. En muchas ocasiones, sobre todo en el caso de los textos "serios", se trata de actos análogos a los que efectuamos los filósofos en nuestros escritos, como someter a consideración una proposición junto con las razones que presuntamente la avalan. Sin embargo, 
también pueden estar incluidas aseveraciones que se clasifican como estrictas, actos destinados a ofrecer conocimiento a través del testimonio: el autor de una ficción realista, Dickens pongamos por caso, ha llevado a cabo una investigación de las circunstancias particulares en cuyo marco sitúa su historia (quizás determinadas prácticas judiciales de su época y lugar) y, confiando en ello, nosotros sus lectores obtenemos conocimiento sobre ese tema a partir de su ficción.

Como Friend señala, esto constituye un problema serio para los análisis griceanos como el de Currie (1990). Hay que decir que los autores griceanos no suelen defender que las ficciones estén constituidas por actos de invitar a la imaginación, sino más bien por la mera imaginación: invitan a imaginar proposiciones que se suponen falsas o, al menos, si son verdaderas, son verdaderas nada más "por casualidad" y no son materias de las que el autor tenga un conocimiento genuino. Currie y otros han tratado de justificar esta idea con experimentos mentales que a muchos no nos parecen convincentes intuitivamente. A mi juicio, su verdadera motivación está en que, en el marco griceano, es difícil distinguir ficción y no ficción de otro modo. La razón es que la imaginación relevante aquí no es la imaginación "de imágenes", sino la de proposiciones (vaya o no asociada a la de imágenes). Ahora bien, una proposición que se imagina bien se puede también creer, y una proposición que se cree bien se puede también imaginar. Invitar a la imaginación es por ello compatible con invitar a la creencia y viceversa. Para distinguir entre ficción y no ficción en sus términos propios, el griceano se ve destinado a apelar a la mera imaginación en el caso de la ficción.

Pero eso causa el problema que Friend señala, del que, por lo demás, Currie (1990) está bien consciente. Su respuesta es que su teoría no pretende más que analizar preferencias, y no obras. Ahora bien, como Friend señala, esta respuesta es insuficiente. En primer lugar, nuestras intuiciones sobre la distinción entre ficción y no ficción se refieren sobre todo a la clasificación de obras. En segundo lugar, o bien la propuesta de Currie no resuelve el problema, si admite proferencias que invitan tanto a la imaginación como a la creencia (como el caso bien conocido de la primera frase de Ana Karenina, "Todas las familias felices se parecen, pero las infelices lo son cada una a su manera"), o bien convierte inadecuadamente lo que clasificamos como ficciones en obras hechas con retazos de ficción y retazos de no ficción. Esto último es erróneo a todas luces: muchas de las proposiciones que configuran el marco de las obras de Dickens, pongamos por caso, o la de Ana Karenina recién citada, cuyos autores las juzgaban verdaderas y que permiten la adquisición de conocimiento 
son manifiestamente partes de la ficción, necesarias para la inferencia de otros contenidos de la obra.

En contraste, la propuesta normativa muestra aquí una de sus virtudes centrales: en este marco, la distinción no estriba en los estados psicológicos involucrados, que en muchos casos pueden ser compatibles, como hemos visto. La distinción estriba en las normas relevantes, que sí distinguen con claridad los tipos en cuestión: algo sujeto a la norma de la verdad puede o no violar la norma de invitar a tener imaginaciones interesantes, algo que fracasa miserablemente cuando se evalúa mediante esta última norma (el prospecto de un medicamento o el manual de un aparato) puede, sin embargo, cumplir fielmente la norma de la verdad.

Pasemos pues, a las críticas de Corbí, quien cita las agudas observaciones de Robert Musil, a través de su personaje Ulrich en El hombre sin atributos, sobre la imbricación de la "teatralidad" en las acciones más cotidianas, la cual proviene del "gusto por la transformación y el disfraz". (Dicho sea de paso, éste es un ejemplo más de la primera observación de Friend, que justifica la posibilidad de aprender a partir de las ficciones, en este caso a propósito de cuestiones filosóficas como las que se abordan aquí y que por ello es pertinente traer a colación.) Con Ulrich/Musil, Corbí cuestiona lo que entiende como el alineamiento de mis propuestas con una conciencia burguesa que escinde el mundo del teatro, que entretiene sus veladas, de la "realidad", que ocupa sus negocios matinales. La norma que defiendo para la ficción:

parece $[\ldots]$ comprometida con esta división entre dos formas de conciencia al subrayar la contraposición entre aseverar y ficcionalizar, que parece asociada a su vez a la contraposición entre observar e imaginar y a la distinción entre lo que somos y lo que fingimos ser. [...Por ello] si concediésemos que el arte de Su Excelencia es también teatral sin que medie tal escisión, entonces deberíamos reconocer que [esa norma] atiende tan sólo a la forma de teatralización propia de la clase media que acude a los teatros, a las iglesias o a sus citas sexuales, pero no daría cuenta de otros modos de teatralización que estarían sujetos a normas o criterios distintos (véanse las pp. 101-103 de este número de Crítica).

Las agudas observaciones de Corbí, y las de Musil en que se apoyan, me recuerdan un buen ejemplo de esa conciencia burguesa escindida: el caso de un amigo (burgués a buen seguro, consejero del Banco de España para más señas) quien me dijo, al saber que en nuestro grupo de investigación tenemos desde hace años un grupo de 
discusión literario, que él carecía de tiempo "para novelas" y que prefería dedicarlo al ensayo y la historia. Sin duda, consideraría una refutación de mis propuestas el que alguien refrendase esta actitud (bien común, por lo demás) respecto de la ficción, ignorante de su profunda imbricación con la vida más "real", más práctica y material que podamos pensar. Incluso a partir de las historias de Alicia (de su relación con los animales y con los otros personajes aún más singulares con que se encuentra en sus viajes) el lector puede obtener conocimiento, psicológico o social pongamos por caso, tan bien o quizás incluso mejor que a partir de ensayos sesudos y veraces sobre los mismos temas. A juzgar por sus biografías, Dodgson estaba - como muchos otros creadores de ficciones, entre los que se encuentra sin duda Musil - tan consciente de la seriedad de sus ficciones como Su Excelencia de la del papel que representa con grácil teatralidad. Trataré, pues, de mostrar que las distinciones que esbocé en la sección anterior permiten recoger adecuadamente la participación de la ficción en el mundo más "real".

La insatisfacción que he expresado por la propuesta de Friend, con la que Corbí parece simpatizar, como ya dije ("No veo por qué esa estrategia explicativa [que vale para los géneros como el naturalismo o el verismo] no podría extenderse al acto de ficcionalizar, aunque se considerase universal"; véase antes, p. 101), requiere que la ficción y la no ficción sean categorías disyuntas, definidas con independencia de las contingencias históricas, las cuales sí definen los géneros. Mi propuesta recoge este desiderátum: como dije antes, las normas que definen ficcionalizar y aseverar distinguen dos tipos de actos en sí mismos diferentes a todas luces, porque remiten a normas distintas, que prohíben lo que el otro permite. Ahora bien, esta propuesta se refiere a la naturaleza de ciertos tipos abstractos. Como expuse en la sección anterior, debemos distinguir la cuestión de cuál es la esencia de tales tipos de la cuestión de qué es lo que hace que algunos de ellos (en particular, a los que nos referimos aquí) estén en vigor en las prácticas de determinada comunidad de individuos.

Como aventuré también, en el caso de tipos como prometer, aseverar y requerir (y los que considero casos particulares de esto último: invitar a una aseveración - preguntar - e invitar a la imaginación - ficcionalizar-), no me parece razonable pensar que la explicación de su vigencia sea una convención, sino que involucra motivaciones morales. Esto es, sin embargo, compatible con el hecho de que haya especificaciones más particulares de esos actos que sí estén en vigor por convención: preguntar por medio de la proferencia de una oración interrogativa es tal vez un acto convencional (pese a ser un recurso 
universal en todos los lenguajes), como sin duda lo es prometer por medio de la proferencia de una oración que comience con la frase "prometo que". En contra de lo que Corbí parece presuponer en el argumento con que concluye el texto citado en el párrafo anterior, el hecho de que determinadas formas de ficcionalizar o aseverar que constituyen propiamente géneros - como, por un lado, la novela histórica tal como se practicaba en la época de Scott y tal como se practica ahora, o el biopic tal como se entendía en el Hollywood clásico y como se entiende ahora, o, por otro lado, la historia tal como se entendía en la Antigüedad clásica y como se entiende hoysean convencionales no requiere que los tipos mismos lo sean, pues, en general, el hecho de que una especificación particular de un tipo normativo sea convencional no requiere que el tipo mismo lo sea.

Además de la cuestión general de qué hace que determinados tipos normativos estén en vigor, para responder cabalmente a Corbí y Friend debemos tomar en consideración qué hace que haya de entenderse que un acto particular entra dentro del tipo y por tanto está sujeto a las normas. Por supuesto, esta cuestión está relacionada con la anterior, porque, pongamos por caso, las convenciones que hacen que determinada práctica convencional (sentenciar a alguien a prisión o bautizar un barco, por ejemplo) esté en vigor pueden especificar también, tan meticulosamente como sea posible, bajo qué circunstancias se lleva a cabo un acto de ese tipo, qué propiedades deben tener los participantes, cuáles deben ser las circunstancias, etcétera.

Como adelanté en la sección anterior, a mi juicio, es aquí cuando las intenciones comunicativas griceanas desempeñan su papel. Incluso cuando alguien utiliza en su sentido plenamente literal una oración que expresa convencionalmente, sin necesidad de apelar al contexto, el contenido con que se compromete, el hablante debe tener la intención de someter su acto a la norma constitutiva del tipo de acto que le indica convencionalmente la oración que utiliza. El modo declarativo de la oración es insuficiente para especificar si el acto se debe tomar como una aseveración o, pongamos por caso, como una conjetura o supuesto, y cabe argumentar que son las intenciones del hablante las que determinan que sea una cosa u otra. Esto es mucho más patente cuando el contenido expresado depende de factores contextuales, cuya especificación requiere indicaciones del hablante (como en el caso de muchos demostrativos) o cuando el hablante lleva a cabo un acto de habla indirecto (como cuando quiere dejar claro que habla irónicamente y, lejos de someterse a la norma correspondiente 
al sentido literal de la oración que utiliza, pretende hacerlo respecto de un contenido contradictorio).

Consideremos ahora en este marco el caso de la teatralidad de $\mathrm{Su}$ Excelencia. Cabe decir que el uso del término "teatral" para describir su comportamiento es aquí meramente metonímico, y con el fin de deshacernos de esa objeción. Análogamente, como ya indicaba Currie (1990, pp. 35-38), el que muchos tratemos la Biblia como ficción no es una objeción a las teorías que apelan a las intenciones ficcionalizadoras del creador de una obra para hacer la distinción entre ficción y no ficción, pues no estamos diciendo en estos casos que la Biblia sea literalmente una ficción, sino sólo que algunos la tratamos como tal o que se puede describir como ficción en un sentido lato, extendido del término.

Sin embargo, considero que esta respuesta a la objeción de Corbí hace poca justicia al interés de la observación de Musil (Ulrich, estrictamente hablando) que la sustenta. Entiendo que se trata de la observación, análoga a las de Friend, que propuse antes, a saber, que la ficción está mucho más imbricada con la realidad de lo que mi amigo consejero del Banco de España parecía capaz de apreciar. Cabe tomar la teatralidad del diplomático — al igual que la de las prácticas de la Iglesia católica - literalmente como una ficción —una apelación a la imaginación de las audiencias respectivas - sin quitarles por ello un ápice de su seriedad (verdaderamente mortal en muchos casos). Tanto Su Excelencia como los oficiantes de la Iglesia pretenden que los imaginemos imbuidos del poder magnífico — de la pompa y circunstancia - que sus acciones exhiben, pero quieren también, en parte por medio de ello, ejercer de hecho un poder tal. Del mismo modo, Flaubert, Musil, James, Proust, Mann y muchos otros grandes novelistas pretenden decirnos realmente con sus ficciones - y lo consiguen muchas veces - tanto o más sobre las aspiraciones y debilidades humanas como el más perspicaz psicólogo, con otros métodos. Una de las funciones centrales de las recreaciones teatrales en The Act of Killing está justamente, a mi juicio, en poner de relieve la eficacia de la reproducción imaginativa para suscitar la contrición por los sucesos de 1965 a 1966 que, según documenta el filme, la sociedad indonesia rehúye.

Creo, sin embargo, que esto no supone una objeción a mi propuesta. Ficción y no ficción son, en sí mismas, entidades cabalmente diferentes. Ya he indicado mis razones más serias para sostenerlo así. Sin embargo, nada impide que un mismo acto particular sea a la vez una ficción y una aseveración: quizás sea primariamente lo uno y 
secundariamente lo otro, quizás sea tanto lo uno como lo otro, quizás esté indeterminado si es lo uno o lo otro. Nada impide tampoco que algo sea una ficción y que contenga partes que sean parte de esa ficción, pero que también contenga aseveraciones. Ana Karenina es una ficción, porque así lo establecen las intenciones comunicativas que manifesta su autor, Tolstoi. El contenido de la primera frase es parte de la ficción - parte de lo que un lector informado debe imaginar y que se debe tomar en consideración para decidir si la obra satisface o no los valores constitutivos de las ficciones-. Ahora bien, una parte de la práctica de producir ficciones con aspiraciones literarias es el que su autor incluya en ellas proposiciones con fuerza constatativa; por ejemplo, proposiciones generales que quiere someter a nuestra consideración, porque las juzga verdaderas. También puede querer que su obra ofrezca razones para creerlas: ejemplos ilustrativos de las diferencias entre las familias infelices, pongamos por caso. Esto vale para el contenido de la primera frase de la obra, que por consiguiente muy bien puede contar también como tal acto aseverativo de someter ese contenido a nuestra consideración, si Tolstoi realmente tenía tal intención al componerla. En mi libro gloso el caso de la novela de Javier Marías Negra espalda del tiempo (1998), la cual pese a ser, a mi juicio, una ficción, por lo que puedo decir bien puede constar de actos de naturaleza aseverativa respecto de todas y cada una de las proposiciones que contiene. Ni las consideraciones de Corbí ni las de Friend antes de él me convencen de que haya algo contradictorio o realmente paradójico en estas propuestas.

Lo mismo se aplica al caso contrapuesto de la no ficción, que Corbí discute en la sección 5 de su discusión. Sin duda, las obras de no ficción incluyen muchos pasajes que constituyen invitaciones a la imaginación, a mi parecer, actos del mismo tipo genérico que ficcionalizar: hay historias contrafácticas en los libros de historia o de ética (como indica Corbí), experimentos mentales en los ensayos filosóficos, metáforas creativas en cualquier ensayo, recreaciones teatrales en los documentales. Sin embargo, de nuevo, es enteramente compatible con la idea de que aseverar y ficcionalizar son en sí mismos actos de tipos diferentes el que una obra que sea sobre todo de no ficción y que se comprometa con normas veritativas respecto de cierto contenido recurra para ello a partes fictivas, las cuales incluso llegan a desempeñar un papel fundamental en el soporte argumentativo de la obra. Esto es justamente lo que sucede, según aventuré antes, con las recreaciones teatralizadas en The Act of Killing, una obra de no ficción en su conjunto. Confío en que quede claro que no estoy haciendo aquí concesión alguna a la que entiendo que es la tesis 
central de Corbí y Friend: en contra de esa tesis, la ficción y la no ficción son, en sí mismas, en su esencia o naturaleza, diferentes entre sí, por más que un acto particular de aseverar (mediante una obra como el documental The Act of Killing o un artículo de filosofía) incluya partes que sean actos de ficcionalizar.

De hecho, si bien las consideraciones de Friend (que Corbí parece compartir) sobre el carácter de los géneros contingentes históricamente de la ficción y la no ficción no son correctas para esas categorías en su verdadera naturaleza, sí lo son (y resultan por ello iluminadoras) en cuanto a la manera en que se establece en el curso del tiempo que un acto debe sujetarse a una $\mathrm{u}$ otra obra. Un lector de Tucídides o Tácito sabe que los discursos y las batallas se deben tomar como ficciones, y que la contribución al acto primario de naturaleza constatativa que esas obras llevan a efecto se debe evaluar también como tal. Un historiador contemporáneo carece de semejante libertad. Un filme biográfico del Hollywood clásico (como los memorables sobre Edison o Pasteur) contiene menos aseveraciones que uno contemporáneo sobre Alan Turing y por ello está sujeto a menos críticas debidas a sus distorsiones de la realidad. Una explicación detallada de esto debe basarse, a mi juicio, en el hecho de que (como señala Grice y muchos otros han desarrollado) las intenciones están costreñidas por la posibilidad racional de que contribuyan a realizar sus objetivos. La cuestión de cuáles son las intenciones (ficcionalizar, aseverar) que tiene un autor depende, así pues, de qué puede esperar razonablemente que entienda su audiencia pretendida.

Mas nada de todo esto, a mi juicio, establece ninguna de las tesis (aparentemente contrapuestas, pero muchas veces complementarias) que muchos de los autores que se han ocupado de estos temas (en escritos filosóficos o fictivos) han tratado de defender, como ilustro en mi libro con diversos ejemplos, desde Nelson Goodman hasta el mencionado de Javier Marías, pasando por Cortázar, Vargas Llosa y otros. A saber, que o bien la ficción y la no ficción son enteramente disyuntas (Marías, Vargas Llosa), o bien se disponen en los extremos de un continuo sin diferencias sustanciales entre sí (Corbí, Cortázar, Friend, Goodman). Y, por las razones antes apuntadas, considero importante mantener la tesis opuesta a ambas, sucintamente formulada y defendida en estas páginas.

Concluiré con dos observaciones relativamente menores. La primera se refiere a la distinción entre ficción y literatura. Esta última categoría, por supuesto, incluye obras de no ficción; entiendo también que la primera es más extensa que la de la ficción literaria, por incluir obras sin pretensión artística alguna (por ejemplo, 
muchos experimentos mentales en la filosofía, además de otras obras de géneros que vienen fácilmente a las mientes). Entiendo que la categoría cuyos contornos he intentado trazar incluye también esas obras y ésta es mi única razón para tomarla como objeto de estudio. Los ejemplos que provocan una discusión más interesante se ofrecen, sin embargo, en las ficciones literarias, en parte por las consideraciones precedentes relativas a la posibilidad de adquirir conocimiento a partir de la ficción. En segundo lugar, debo rechazar la sugerencia que hace Corbí en las páginas finales de su discusión, en cuanto a la dependencia de la ficción respecto de la narratividad — que, según entiendo, consiste en presentar sucesos junto con sus relaciones causales y explicativas-. Por supuesto que muchas ficciones son narrativas en ese sentido, pero hay, a mi juicio, ficciones no narrativas (muchas pinturas, por ejemplo) y narraciones no fictivas (muchos documentales y libros de historia).

El texto de Corbí contiene muchos otros aspectos que merecerían glosa, pero daré aquí por concluida esta réplica, agradeciendo de nuevo la ocasión que con su discusión me ha ofrecido de intentar articular con mayor claridad mis propuestas. ${ }^{3}$

\section{BIBLIOGRAFÍA}

Caryl, Christian, 2015, "Saving Alan Turing from His Friends", New York Review of Books, vol. 62, no. 2, pp. 19-21.

Currie, Gregory, 1990, The Nature of Fiction, Cambridge University Press, Cambridge.

Davis, Wayne, 2003, Meaning, Expression, and Thought, Cambridge University Press, Cambridge.

Friend, Stacie, 2014, "Believing in Stories", en Gregory Currie, Matthew Kieran, Aaron Meskin y Jon Robson (comps.), Aesthetics and the Sciences of Mind, Oxford University Press, Oxford, pp. 227-247.

- 2011, "Fictive Utterance and Imagining", Proceedings of the Aristotelian Society, vol. 85 sup., no. 1, pp. 163-180.

— 2008, "Imagining Fact and Fiction", en Kathleen Stock y Katherine Thomson-Jones (comps.), New Waves in Aesthetics, Palgrave MacMillan, Basingstoke, pp. 150-169.

García-Carpintero, Manuel, 2016a, "To Tell What Happened as Invention:

Literature and Philosophy on Learning from Fiction", en Andrea Selleri

${ }^{3}$ Mis ideas sobre las cuestiones que abordo en este trabajo se han clarificado notablemente gracias a diversas conversaciones con Josep Corbí. Para elaborar esta discusión me he beneficiado de ayudas de la DGI, FFI2013-47948-P, y de la Direcció General de Recerca, Generalitat de Catalunya, a través del premio ICREA Acadèmia 2013. 
y Philip Gaydon (comps.), Literary Studies and the Philosophy of Literature: New Interdisciplinary Directions, Palgrave Macmillan, Londres, pp. 123-147.

García-Carpintero, Manuel, 2016b, "Recent Debates on Learning from Fiction", Teorema, vol. 35, no. 3, pp. 5-20.

vol. 53, no. 3, pp. 339-357.

[por aparecer].

Grice, H. Paul, 1975(1991), "Logic and Conversation", en Peter Cole, Jerry L. Morgan y John P. Kimball (comps.), Syntax and Semantics, vol. 3, Speech Acts, Academic Press, Londres, pp. 41-58. [Versión en castellano: "Lógica y conversación", trad. Juan José Acero, en Luis M. Valdés Villanueva (comp.), La búsqueda del significado, Tecnos, Madrid, 1991, pp. 520-538.]

Kripke, Saul, 1980, Naming and Necessity, Harvard University Press, Cambridge, Mass.

Lewis, David, 1975(1983), “Languages and Language”, en Keith Gunderson (comp.), Language, Mind and Knowledge, University of Minnesota Press, Minnesota, pp. 3-35 [reimp. en Philosophical Papers, Oxford University Press, Oxford, 1983, vol. 1, pp. 163-188].

Neill, Alex y Aaron Ridley, 2012, "Relational Theories of Art: The History of an Error", British Journal of Aesthetics, vol. 52, no. 2, pp. 141-151.

Rawls, John, 1955, "Two Concepts of Rules", The Philosophical Review, vol. 64, no. 1, pp. 3-32.

Scanlon, Thomas M., 2003, "Promises and Contracts", The Difficulty of Tolerance: Essays in Political Philosophy, Cambridge University Press, Cambridge, pp. 234-269.

Searle, John, 1969, Speech Acts: An Essay in the Philosophy of Language, Cambridge University Press, Cambridge.

Strawson, Peter, 1964, "Intention and Convention in Speech Acts", The Philosophical Review, vol. 73, no. 4, 439-460.

Walton, Kendall, 1970, "Categories of Art", Philosophical Review, vol. 79, no. 3, pp. 334-367.

Williamson, Timothy, 1996(2000), "Knowing and Asserting", Philosophical Review, vol. 105, no. 4, pp. 489-523 [incluido con revisiones como "Assertion", en Knowledge and Its Limits, Oxford University Press, Nueva York, 2000, pp. 238-269; las referencias se hacen a esta última versión].

Recibido el 30 de enero de 2017; revisado el 17 de marzo de 2017; aceptado el 8 de abril de 2017. 